\title{
NÚCLEOS DE DESERTIFICAÇÃO NO ESTADO DA PARAIIBA
}

\section{Nucleous of desertification in Paraíba State}

\author{
Jose Jakson Amancio ALVES ${ }^{1}$ \\ Edílson Nóbrega de SOUZA² \\ Sebastiana Santos do NASCIMENTO
}

\begin{abstract}
RESUMO
O presente trabalho aborda a problemática dos núcleos de desertificação na Paraíba que diretamente está relacionada ao antropismo na caatinga e nas condições ambientais e fitogeográficas desse geossistema. O domínio geoecológico das caatingas se estende por cerca de $1037.517,80 \mathrm{~km}^{2}$, sob as latitudes subequatoriais, compreendidas entre $2^{\circ} 45^{\prime}$ e $17^{\circ}$ 21 ' LS. Sua área corresponde a $54 \%$ da Região Nordeste e a $11 \%$ do território brasileiro, constitui o chamado Polígono das Secas. Na caatinga as espécies lenhosas chamam a atenção por suas formas biológicas e pela posição dominante na estrutura da formação. Em função da magnitude dessas características, esse corresponde ao maior problema na geração dos núcleos de desertificação no estado da Paraíba. Essas espécies lenhosas de porte raquítico são as mais apreciadas para a queima em carvoarias, fornos de padarias, etc. Tratam-se de fácies mais secas e degradadas das caatingas. Um outro aspecto a observar é que a fragilidade natural desse ecossistema traz sérias consequências para os geótopos e para as biocenoses, como também, a prática da devastação de grandes espaços pelas queimadas para as áreas de pastagem, provocando grande desequilíbrio no ecossistema e contribuindo com o processo de degradação das terras. Esse trabalho aponta uma série de levantamentos que enfatizam esse processo no estado da Paraíba, como também, uma contribuição para minimização dos seus efeitos.
\end{abstract}

Palavras-chave: Caatinga; Degradação Ambiental; SemiÁrido.

\begin{abstract}
The present paper presents the discussion about the nucleous of desertification in Paraíba which is directly related to degradation produced by men in the stunted sparse forest and in the environmental and fitogeographical conditions of this same geosystem. The geoecological domain of the stunted sparse forests extends for about $1037.517,80 \mathrm{~km}^{2}$, under the latitudes between tropics, comprehended between $2^{\circ} 45^{\prime}$ and $17^{\circ} 21^{\prime}$ LS. Its area corresponds to $54 \%$ of the Northeast region and to $11 \%$ of the Brazilian territory; it constitutes the droughts called polygon. In the stunted sparse forest the woody species calls the attention for their biological forms and by the dominant position in the formation structure. In magnitude function of these characteristic, those biological forms correspond to the largest problem in desertification cores generation in the $\mathrm{Pa}$ raíba State. These woody species of rickety postage are the most appreciated for the burning in coal-pits, bakeries oven, etc. They are more drought and degraded facies of the stunted sparse forests. Another aspect to observe is the natural fragility of this ecosystem that brings serious consequences for geotops and for biocenoses, as well as the devastation practice of great spaces by the burnt for the pasture areas, provoking great unbalance in the ecosystem and contributing with the land's degradation process. That work points at a series of surveys that emphasize that process in Paraíba State, as well as a contribution to the minimization of its effects.
\end{abstract}

Keywords: Sparse Forest; Environmental Degradation; Semi Arid. 


\section{INTRODUÇÃO}

O processo de desertificação no mundo tem-se intensificado devido às ações antrópicas, em que o aumento da população mundial e do "mega" consumo que tem feito com que a exploração dos recursos naturais para a sobrevivência e comercialização contribuísse para a expansão das áreas que estão em processo de desertificação.

Em grandes áreas a exploração se dá de forma incontrolável, onde usos inadequados dos recursos naturais têm sido motivos de muita preocupação no mundo inteiro, surgindo Conferencias, Convenções, Congressos, e Publicações diversas para debater esta questão. No mundo muitas áreas estão desertificadas e outras em processo. No Brasil, as áreas que estão susceptíveis à desertificação se encontram dentro do Polígono da Secas, que abrange a maior parte do Nordeste brasileiro e uma pequena parte do Sudeste. $\mathrm{Na}$ Conferência de Estocolmo foi constatada a necessidade de um evento específico para tratar o problema da desertificação. Decidiu-se pela convocação da Conferência das Nações Unidas sobre Desertificação, realizada em 1977, na cidade de Nairobi, Kênia. Esta Conferência teve um papel fundamental em todo o processo de luta contra a desertificação no mundo e, dentre eles podese citar: (i) a consolidação do tema em nível mundial permitiu que muitos países atentassem para seus problemas ambientais; (ii) a introdução das regiões com climas áridos e semiáridos no cenário das discussões, mostrando que os recorrentes problemas de pobreza e meio ambiente necessitavam de um enfrentamento direto pela comunidade internacional; (iii) Criação do Plano de Ação Mundial contra a Desertificação.

A despeito desses fatos, os resultados concretos, em termos da aplicação de recursos e reversão dos processos de degradação, foram bastante modestos. Isso foi constatado em 1991, quando o Programa das Nações Unidas para o Meio Ambiente (PNUMA) fez uma avaliação das ações empreendidas no âmbito do Plano de Ação Mundial, constatando o fraco desempenho do mencionado plano.

Com esses resultados, vários países com problemas de desertificação, especialmente na África, decidiram propor a elaboração de uma Convenção sobre o assunto durante a realização da Conferência das Nações Unidas sobre Meio Ambiente e Desenvolvimento (ECO-92). A Convenção é um instrumento jurídico mais forte, pois obriga os países que a assinam a assumir uma série de compromissos, ao contrário de uma Conferência, onde a adesão é voluntária.

Dessa maneira, a Convenção Internacional das
Nações Unidas de Combate à Desertificação nos países afetados por seca grave e/ou desertificação, particularmente na África (CCD), após muitas negociações, entrou em vigor em 26 de dezembro de 1996. O Brasil tornou-se parte da CCD em 25 de junho de 1997 e, em março de 2002, mais de 179 países já faziam parte da Convenção. Hoje, a principal obrigação desses países Partes é elaborar um Programa de Ação Nacional de Combate à Desertificação (PAN).

Sobre o conceito de desertificação, Alves (2007b, p.87) define etimologicamente a:

desertificação como derivado de duas palavras latinas: (i) desertus, adjetivo, particípio passado do verbo desere (desertar, deixar, abandonar), significando, abandonado, desabitado, inculto, selvagem e, desertus, substantivo que quer dizer, solidão, desolação, área vazia; (ii) e fixação, sufixo verbal proveniente da forma passiva do verbo latino ficare (ficeri), ação de fazer, ser feito, ser produzido.

Suertegary (1996, p. 251) citou que o:

termo desertificação foi utilizado por Aburéville pela primeira vez, para expressar a regressão da selva equatorial africana pelo corte abusivo, incêndios e roças para a transformação de campos de cultivo e pastiçais o resultado desta prática não era outro senão a exposição do solo, a erosão hídrica, eólica e conversão de terras biologicamente produtivas em "desertos".

Também, sobre o conceito de desertificação, este já havia de certo modo sido esboçado no Brasil por Euclides da Cunha, em 1901, em dois ensaios jornalísticos escritos por ocasião de uma viagem de trem entre o Rio de Janeiro e São Paulo, intitulado: "Fazedores de Desertos" e "Entre Ruínas". Neles são descritas as pilhas de lenha amontoadas ao longo da estrada de ferro, provenientes da Mata Atlântica e as encostas laceradas por voçorocas com as rochas expostas nas terras antes ocupadas pelas plantações de café, e que foram abandonadas.

Apesar das várias definições oficiais oriundas de diversos organismos internacionais de combate à desertificação, existem mais de 130 definições recobrindo os diversos campos transdisciplinares que tratam do problema. Porém, a Conferência das Nações Unidas sobre Desertificação começa a partir do ano de 1977 os estudos conceituais sobre desertificação e, em julho de 1992, conclui desertificação como sendo: "degradação das terras em áreas áridas, semi-áridas e 
ALVES, J. J. A.; SOUZA, E. N.; NASCIMENTO, S. S. Núcleos de desertificação...

subúmidas seca resultando de vários fatores inclusive das variações climáticas e das atividades humanas" (UNCOD, 1977).

Para Mainguet (1992, p. 425):

a desertificação é revelada pela seca, que se deve às atividades humanas quando a capacidade de carga das terras é ultrapassada; ela procede de mecanismos naturais que são acelerados ou induzidos pelo homem e se manifesta através da degradação da vegetação e dos solos e provoca na escala humana de uma geração, (25-30 anos), uma diminuição ou destruição irreversível do potencial biológico das terras e de sua capacidade de sustentar suas populações.

Essa definição pode ser a mais abrangente, pois enfatiza as causas humanas e os parâmetros climáticos, sobretudo a seca, agindo como reveladores dos processos de degradação. Como conclusão, compreende-se que a desertificação é uma crise ambiental cujo término é o surgimento de paisagens desérticas, caracterizada pela degradação com o desaparecimento irreversível de algumas espécies vegetais e pelo esgotamento definitivo dos planos de água superficiais, baixa dos lençóis freáticos e pelo aumento da degradação dos solos em virtude de uma exarcebação dos processos de erosão hídrico e eólico.

Na visão de Drew (1998, p.14):

desertificação é um vocábulo de significado amplo, que inclui várias alterações climáticas, ecológicas e geomoforlógicas que diminuem a produtividade biológica de uma área tornando-a enfim inaproveitável para a agricultura.

Bertoni e Neto (1999, p.13) também descrevem este processo ao discorrer sobre a degradação dos solos afirmam que:

os solos em que os homens tentam fundar novas civilizações estão desaparecendo, levados pela água e varridos pelos ventos. Atualmente, a destruição da finíssima camada viva do planeta aumenta numa proporção não igualada na história. E quando essa delgada camada - o solo - desaparecer, as regiões férteis que existiram serão desertos inabitáveis.

Por fim, desertificação é um fato que deve ser entendido com fenômeno integrador de processos econômicos, sociais e naturais e /ou induzidos que destroem o equilíbrio dos solos, da vegetação, do clima e da água, bem como a qualidade de vida nas áreas sujeitas a uma aridez edáfica e/ou climática.

\section{INDICADORES DE ÁREAS SUSCEPTÍVEIS À DESERTIFICAÇÃO (ASD)}

As Áreas Susceptíveis à Desertificação (ASD) no Brasil cobrem uma área superior à compreendida pela Região Semiárida ou ao espaço do Polígono das Secas. Na pratica são os meios semiáridos e seus entornos.

De acordo com Alves (2007a, p. 60):

\begin{abstract}
os meios semi-áridos caracterizam-se pela ocorrência de uma crise climática sazonal que repercute em todos os elementos que compõem o seu complexo sistema físico-natural e humano. Com a introdução do homem no sistema semi-árido, aborda-se, obrigatoriamente, o problema das pressões que suas atividades diretas ou indiretas exercem sobre ele, que deixa de ser um complexo de relações entre componentes bióticos e abióticos e se transforma em um geossistema, isto é, como um complexo natural, histórico e social.
\end{abstract}

Em seu interior estão incluídos os municípios caracterizados como semiáridos e subúmidos secos, aos quais foram agregados, em caráter preliminar e os situados no entorno das áreas semiáridas e subúmidas secas.

Para determinação das áreas da ASD, além do critério do Índice de Aridez, as áreas em processo de desertificação são identificadas também a partir do uso de indicadores relacionados à propriedade e uso dos solos em áreas com isoietas pluviométricas, situadas no limite de $500 \mathrm{~mm}$. Essa metodologia foi utilizada por pesquisadores da Empresa Brasileira de Pesquisa Agropecuária (EMBRAPA). Nesse sentido, foram estabelecidos níveis de degradação ambiental (severo, acentuado, moderado e baixo), segundo os tipos de associações de solos (bruno não cálcicos, litólicos etc.), o relevo (suave ondulado, ondulado etc.), a sensibilidade à erosão (forte, muito forte, moderada) e o tempo de ocupação do solo (longo, médio, recente).

A partir daí foram calculados os percentuais dos níveis de degradação ambiental, como mostrados na Tabela 1. A soma das áreas consideradas como submetidas a níveis de degradação "severa" e "acentuada" corresponde a $48,65 \%$. Representa, assim, quase uma vez e meia o valor das áreas consideradas como em situação "grave" e "muito grave", mostradas na Tabela 2. 
ALVES, J. J. A.; SOUZA, E. N.; NASCIMENTO, S. S. Núcleos de desertificação...

TABELA 1 - NÍVEIS DE DEGRADAÇÃO AMBIENTAL POR INDICADORES

\begin{tabular}{|c|c|c|c|c|c|}
\hline $\begin{array}{c}\text { NÍVEIS DE } \\
\text { DEGRADAÇÃO } \\
\text { AMBIENTAL }\end{array}$ & $\begin{array}{c}\text { TIPOS } \\
\text { ASSOCIAÇÕES } \\
\text { DE SOLOS }\end{array}$ & RELEVO & $\begin{array}{c}\text { SENSIBILIDADE } \\
\text { À EROSÃO }\end{array}$ & $\begin{array}{l}\text { TEMPO DE } \\
\text { OCUPAÇÃO }\end{array}$ & $\begin{array}{c}\text { ÀS ÁREAS } \\
\text { SECAS DO } \\
\text { SEMIÁRIDO DO } \\
\text { NORDESTE (\%) }\end{array}$ \\
\hline Severo & $\begin{array}{l}\text { bruno não } \\
\text { cálcico }\end{array}$ & $\begin{array}{l}\text { Suave on- } \\
\text { dulado e } \\
\text { Ondulado }\end{array}$ & Forte & $\begin{array}{l}\text { Longo (Al- } \\
\text { godão) }\end{array}$ & 38,42 \\
\hline Acentuado & Litólicos & $\begin{array}{l}\text { Ondulado, } \\
\text { Forte ondulado } \\
\text { e Montanhoso }\end{array}$ & Muito forte & $\begin{array}{l}\text { Recente } \\
\text { (Cultura } \\
\text { de sub- } \\
\text { sistência) }\end{array}$ & 10,23 \\
\hline Moderado & $\begin{array}{l}\text { Podzólico } \\
\text { eutrófico, } \\
\text { Terra roxa } \\
\text { estruturada, } \\
\text { Cambissolo } \\
\text { ondulado } \\
\text { e Forte } \\
\text { ondulado }\end{array}$ & $\begin{array}{l}\text { Ondulado } \\
\text { e Forte } \\
\text { Ondulado }\end{array}$ & Moderado & $\begin{array}{l}\text { Longo (Cul- } \\
\text { turas } \\
\text { Comerciais) }\end{array}$ & 10,21 \\
\hline Baixo & Planossolos & $\begin{array}{c}\text { Plano e Suave } \\
\text { ondulado }\end{array}$ & Moderado & $\begin{array}{c}\text { Médio } \\
\text { (Pastagem } \\
\text { e Cultura de } \\
\text { subsistências) }\end{array}$ & 7,07 \\
\hline
\end{tabular}

FONTE: PAN Brasil, 2005

Nota-se que a classificação extrema (severa e muito grave) apresenta forte discrepância; da mesma maneira, o nível "moderado" e "baixo" que apresenta forte divergência, não só devido ao método ou foco geográfico, mas também devido aos indicadores escolhidos, quase sempre centrados no problema da erosão.

De todo modo, os dados da Tabela 2, informa que $74,34 \%$ da região semiárida do Nordeste encontram-se submetidos a alterações ambientais variadas, correspondentes ao grau "moderado" (40,80\%), "grave" $(27,68 \%)$ e "muito grave" $(5,86 \%)$.

No total, as ASD cobrem uma superfície de $1.340 .863 \mathrm{~km}^{2}$, como consta da Tabela 3 . O território das
ASD representa $74,46 \%$ da superfície do Nordeste da Sudene. Em 1991, viviam 28.635.498 pessoas nessas áreas. Desse total, $54,69 \%$ residiam em áreas urbanas e $45,31 \%$ no meio rural. Já em 2000 , a população residente nas ASD chegou ao patamar de 31.663.671 habitantes. Sua distribuição, segundo a estrutura domiciliar, em 2000 , foi de $62,19 \%$ em áreas urbanas e $37,81 \%$ no campo. A densidade demográfica nas ASD era de 23,66 hab. $/ \mathrm{km}^{2}$, em 2000, inferior à do Nordeste como um todo, que era de $30,72 \mathrm{hab} / \mathrm{km}^{2}$, naquele mesmo ano. O número de municípios das ASD é de 1.482, como consta da Tabela 4. 
ALVES, J. J. A.; SOUZA, E. N.; NASCIMENTO, S. S. Núcleos de desertificação...

TABELA 2 - ÁREA E POPULAÇÃO AFETADA PELA DESERTIFICAÇÃO NO SEMIÁRIDO

\begin{tabular}{|c|c|c|c|c|}
\hline \multirow{2}{*}{$\begin{array}{c}\text { GRAU DE } \\
\text { COMPROMETIMENTO }\end{array}$} & \multirow[t]{2}{*}{ ÁREA (KM²) } & \multirow{2}{*}{$\begin{array}{c}\text { POPULAÇÃO } \\
\text { EM } \\
1991 \text { (HAB.) }\end{array}$} & \multicolumn{2}{|c|}{ \% DO SEMIÁRIDO } \\
\hline & & & ÁREA & POPULAÇÃO \\
\hline Muito Grave & $52.425,00$ & 1.378 .064 & 5,86 & 7,72 \\
\hline Grave & $247.831,00$ & 7.835 .171 & 27,68 & 43,90 \\
\hline Moderado & $365.287,00$ & 6.535 .534 & 40,80 & 36,62 \\
\hline Total & $665.543,00$ & 15.748 .769 & 74,34 & 88,24 \\
\hline
\end{tabular}

FONTE: PAN Brasil, 2005

TABELA 3 - ÁREA, POPULAÇÃO E NÚMERO DE MUNICÍPIOS NO NORDESTE DA SUDENE, NAS DIFERENTES DELIMITAÇÕES DO SEMIÁRIDO E NAS ÁREAS SUSCEPTÍVEIS À DESERTIFICAÇÃO (ASD), EM 2000,2004* E 2005*

\begin{tabular}{ccc|c}
\hline ESPECIFICAÇÃO & ÁREA $\left(\mathrm{KM}^{2}\right)$ & $\begin{array}{c}\text { POPULAÇÃO } \\
\text { TOTAL (HAB.) }\end{array}$ & $\begin{array}{c}\mathrm{N}^{\circ} \text {. DE } \\
\text { MUNICÍPIOS }\end{array}$ \\
\hline $\begin{array}{c}\text { 1. Polígono das Secas } \\
\text { 2. Região Semiárida do FNE }\end{array}$ & $958.819,60$ & 27.863 .392 & 1.264 \\
3. Bioma Caatinga & $982.563,3^{* *}$ & $22.000000^{* *}$ & $1.133^{* *}$ \\
4. Áreas Susceptíveis à Desertificação ASD & $1.340 .863^{*}$ & 28.098 .321 & 1.280 \\
5. Nordeste da Sudene & $1.037 .517,80$ & 31.663 .671 & 1.482 \\
\hline
\end{tabular}

FONTE: PAN Brasil, 2005 e MMA,2007

No Brasil as áreas susceptíveis a desertificação estão além do Polígono das Secas, englobando os estados de Maranhão, Piauí, Ceará, Rio grande do Norte, Paraíba, Pernambuco, Alagoas, Sergipe, Bahia, Minas Gerais, Espírito Santo, como pode ser observado na Tabela 4. Esses espaços na ASD abrangem um total de 1.482 municípios, dos quais 38,42\% apresentam um nível de degradação ambiental "severo" ligado à monocultura; 5,86\% em condição de "muito grave" em relação ao grau do território comprometido do semiárido nordestino. Em relação aos estados com maior número de municípios vulneráveis na $\mathrm{ASD}$, podemos observar na Tabela 4 que o Ceará apresentou 100\% de comprometimento do seu território, em segundo o Piauí (96,85\%), terceiro Rio Grande do Norte $(94,61 \%)$ e Paraíba com 93,27\% em quarto lugar. 
ALVES, J. J. A.; SOUZA, E. N.; NASCIMENTO, S. S. Núcleos de desertificação...

TABELA 4 - NÚMERO DE MUNICÍPIOS DAS ÁREAS SUSCEPTÍVEIS À DESERTIFICAÇÃO POR ESTADO

\begin{tabular}{|c|c|c|c|c|c|c|}
\hline \multirow[b]{2}{*}{ ESTADO } & \multicolumn{6}{|c|}{$\begin{array}{c}\text { NÚMERO DE MUNICÍPIOS DAS ÁREAS SUSCEPTÍVEIS À } \\
\text { DESERTIFICAÇÃO - ASD }\end{array}$} \\
\hline & $\begin{array}{l}\text { ÁREAS } \\
\text { SEMIÁRIDAS }\end{array}$ & $\begin{array}{l}\text { ÁREAS } \\
\text { SUBÚMIDAS } \\
\text { SECAS }\end{array}$ & $\begin{array}{l}\text { ÁREAS DO } \\
\text { ENTORNO }\end{array}$ & $\begin{array}{l}\text { TOTAL } \\
\text { DAS ASD }\end{array}$ & $\begin{array}{c}\text { TOTAL DE } \\
\text { MUNICÍPIOS } \\
\text { NO ESTADO }\end{array}$ & $\begin{array}{c}\% \text { DO } \\
\text { TOTAL DE } \\
\text { MUNICÍPIOS } \\
\text { NO ESTADO }\end{array}$ \\
\hline Maranhão & - & 01 & 26 & 27 & 217 & 12,44 \\
\hline Piauí & 96 & 48 & 71 & 215 & 222 & 96,85 \\
\hline Ceará & 105 & 41 & 38 & 184 & 184 & 100 \\
\hline $\begin{array}{l}\text { Rio Grande } \\
\text { do Norte }\end{array}$ & 143 & 12 & 03 & 158 & 167 & 94,61 \\
\hline Paraíba & 150 & 47 & 11 & 208 & 223 & 93,27 \\
\hline Pernambuco & 90 & 39 & 06 & 135 & 185 & 72,97 \\
\hline Alagoas & 33 & 13 & 07 & 53 & 102 & 51,96 \\
\hline Sergipe & 06 & 28 & 14 & 48 & 75 & 64 \\
\hline Bahia & 159 & 107 & 23 & 289 & 417 & 69,30 \\
\hline Minas Gerais & 22 & 61 & 59 & 142 & 853 & 16,7 \\
\hline Espírito Santo & - & - & 23 & 23 & 78 & 29,5 \\
\hline TOTAL & 804 & 397 & 281 & 1.482 & 931 & - \\
\hline
\end{tabular}

FONTE: PAN Brasil, 2005, adaptado por Alves et al (2008).

\section{NÚCLEOS DE DESERTIFICAÇÃO}

O processo da desertificação passou a ser estudado no Brasil na década de 1970. A maioria dos estudiosos concorda que a desertificação é resultante de vários fatores, incluindo variações climáticas e atividades humanas. A resultante do antropismo é principalmente a erosão, particularmente a laminar (com eventuais ocorrências de pequenas áreas afetadas pela erosão em sulcos ou "voçorocas") e os processos de salinização do solo, tanto em áreas de agricultura de sequeiro como de agricultura irrigada. Iniciando com a destruição da cobertura vegetal natural e, por interações das atividades antrópicas com as variações de clima e tempo, são criadas as condições materiais para o estabelecimento dos processos de desertificação.
Para Vasconcelos Sobrinho (1983, p.25) as áreas submetidas a processos de desertificação no semiárido brasileiro:

apresentam-se com uma fisionomia típica denunciadora, facilmente percebida. Nas áreas afetadas, a vegetação se apresenta de porte reduzido, algumas espécies com sintomatologia de nanismo e concentração diluída, ou seja, com maior permeabilidade do que nas demais áreas, geralmente coincidindo com a presença da caatinga hiperxerófita. Nesse tipo de caatinga e solo a desertificação pode surgir espontaneamente, havendo, pois, a possibilidade de sua preexistência no Nordeste, antes do aparecimento do colonizador. 
Toda a caatinga hiperxerófita é uma área presumivelmente comprometida com o processo de desertificação, o qual se acentua a cada estio anual e, principalmente, após cada seca. Quando o período chuvoso volta, verifica-se um esforço de recuperação que nem sempre é recompensado integralmente.

Entre os fatores responsáveis pela ocorrência dos processos de desertificação, merece destaque um dos seus desdobramentos que é a destruição dos estoques de sementes, como resultado da degradação da cobertura vegetal nativa de uma dada área. Vasconcelos Sobrinho (1983, p. 26) relatou que:

na região das caatingas nordestinas os frutos amadurecem ao fim da época das chuvas, quase que generalizadamente, na maioria das espécies arbóreas e herbáceas, permanecendo pendentes dos ramos durante algum tempo. Ao se desprenderem e caírem no solo, não germina de imediato, pois a resistência da casca e outros artifícios da natureza impedem a germinação pronta. Se germinassem, morreriam quase em seguida, não resistindo à longa estação seca e quente da estiagem, com interrupção brusca e total das chuvas. A germinação, porém, processa-se rapidamente logo ao caírem às primeiras chuvas, pois os indumentos foram intensamente desgastados pelo intemperismo.

As queimadas realizadas para a preparação de novos terrenos de cultivo desempenham papel de grande poder destruidor do ambiente. "Compreende-se, pois, que a restauração da cobertura vegetal depende da preservação desses estoques de sementes" (VASCONCELOS SOBRINHO, 1983, p. 31).

Uma outra evidência marcante sobre a ocorrência de processos de desertificação é dada pela forma com que aparecem determinadas manchas de solo no semiárido nordestino. Essas manchas apresentam-se descarnadas, como espécies de erupções epidérmicas. São áreas de solos rasos, quase que reduzidas ao afloramento rochoso, sem capacidade de retenção de água, pois, cessadas as chuvas, elas ficam imediatamente desidratadas. Os solos dessas áreas também apresentam deficiências em matéria de nutrientes, que contribuem para potencializar sua vocação para a desertificação. O clima é o mesmo das áreas mais próximas, observando-se as diferenças específicas em função do tipo de solo. Significa dizer que, ao lado dos fatores gerais que comandam os processos de desertificação, há fatores locais determinados pelas condições de solo. "Por isso é possível encontrar manchas férteis de solos ao lado de manchas desertificadas ou em processo de desertificação" (VASCONCELOS SOBRINHO, 1983, p. 26). É a ocorrência - isolada ou agregada - dessas manchas que comanda o processo de constituição das áreas denominadas por Vasconcelos Sobrinho como Núcleos de Desertificação.

De amplitude variada, as manchas que indicam a formação desses núcleos apresentam o horizonte principal do solo fortemente erodido (restrito ao afloramento rochoso). Nesses locais a vegetação recupera-se pouco ou não se recupera, mesmo nos períodos de chuva. Os Núcleos de Desertificação têm uma dupla importância conceitual: "ora se caracterizam como o efeito máximo do processo de degradação ambiental, ora representam seu indicador mais importante" (VASCONCELOS SOBRINHO, 1983, p. 27). Esses núcleos apresentam a tendência de se expandirem, em detrimento das áreas vizinhas.

Os Núcleos de Desertificação também podem ser encontrados de forma isolada, fora de áreas degradadas. São os chamados Núcleos de Desertificação Solitários, constituídos como resultado direto da ação antrópica. Esses núcleos ocorrem em áreas cultivadas intensa e ininterruptamente. Os Núcleos Solitários também surgem como resultado da "tomada de empréstimo" de terras marginais às rodovias, para a construção das pistas de rolamento. Suas áreas têm recuperação difícil, pois possuem uma constituição feita à custa da retirada total do solo.

Com a colaboração do prof. Vasconcelos Sobrinho, a SUDENE iniciou, em 1977, o estudo das áreas em processo de desertificação. Esse estudo tinha em vista identificar as áreas mais atingidas pelo fenômeno e selecionar as consideradas mais críticas. Foi constatado que a causa principal para a intensa degradação dessas áreas foi a substituição da caatinga pela agricultura e pecuária, bem como pela mineração (Gilbués), extração de argila de solos aluviais (Seridó) e da retirada da madeira para lenha. Essas áreas foram caracterizadas como de alto risco à desertificação, e ficaram conhecidas como núcleos desertificados, a saber: Gilbués, Irauçuba, Seridó e Cabrobó.

Para Santos e Lima (2004, p. 49):

o impacto da desertificação nesses quatro núcleos é variável, pois a natureza geológica e os tipos de solos também são distintos. Os solos no Núcleo de Gilbués pertencem à classe dos Latossolos e Podzólicos (Argissolos), enquanto os de Irauçuba são da classe dos Planossolos. No Núcleo do Seridó predominam os tipos Bruno Não Cálcico, Litólico, Solonetz Solodizado e Aluvião. No Núcleo de Cabrobó os solos são arenosos, permeáveis e não retêm as águas da chuva em condições de serem utilizadas pelas plantas. 
O processo de ocupação das áreas onde estão situados esses núcleos também varia de um para outro, ainda que as atividades predominantes estejam quase que totalmente ligadas à agropecuária. As exceções ficam por conta dos Núcleos de Gilbués e do Seridó, onde a exploração mineral desempenha um relevante papel econômico, mas também contribuiu fortemente para ampliar o processo de desertificação.

Por fim, os núcleos de desertificação são áreas isoladas cujas condições de degradação da vegetação e solos (erosão hídrica, química) denunciam claramente a diminuição de sua capacidade produtiva. Esses núcleos de desertificação constituem pequenas áreas de formas variadas e pontuais, lineares e areolares - em que os solos apresentam-se fortemente degradados: 0 horizonte superficial decapitado pela erosão laminar ou retalhados pelos ravinamentos, alguns destes chegam a ser medianamente profundos (nas acumulações coluviais dos pés-de-serra, e dos terraços fluviais) e por vezes, por certos movimentos de massa de pequena dimensão.

Nesses locais a vegetação se recupera muito dificilmente ou então é substituída por algumas espécies mais xerófilas da caatinga. "Uma outra observação, é que os núcleos de desertificação possuem dinamismo próprio baseado na morfodinâmica característica do sistema semiárido e têm uma tendência a evoluir em detrimento das áreas vizinhas por processos regressivos de erosão" (MATALLO JÚNIOR, 2001, p. 79). Além disso, eles podem ser dotados de elevado potencial de degradação, dependendo das condições ecotópicas e podem ser localizados ou generalizados. Sua tendência evolutiva no tempo e no espaço pode ser rápida, muito rápida, lenta ou incipiente. Em alguns casos observados a degradação já se encontra em um estágio muito avançado, talvez irreversível.

\section{ESPACIALIDADE DA DESERTIFICAÇÃO NA PARAÍBA}

O Estado da Paraíba, geograficamente se situa entre os meridianos de $34^{\circ} 45^{\prime} 54^{\prime \prime}$ e $38^{\circ} 45^{\prime} 45^{\prime \prime}$ a oeste de Greenwich, e os paralelos de 6 ${ }^{\circ} 02^{\prime} 12^{\prime \prime}$ e $8^{\circ} 19^{\prime} 18^{\prime \prime}$ de latitude sul, no nordeste oriental do Brasil, limitando-se ao norte com o Estado do Rio Grande do Norte, ao sul com o estado de Pernambuco, ao oeste com o Ceará, e ao leste com o oceano atlântico. A maior extensão é na direção leste-oeste, com uma distância angular de $3^{\circ} 59^{\prime} 51^{\prime \prime}$ e uma distância linear de 443 km. A distância angular na direção norte-sul é de $2^{\circ} 17^{\prime}$ 06" medindo linearmente $253 \mathrm{~km}$ de extensão. A área do Estado é de $56.372 \mathrm{Km}^{2}$ ficando situado praticamente no que se convenciona chamar de "polígono das Secas" do qual a Paraíba ao nível de Nordeste ocupa $5,88 \%$, ou seja, $97,78 \%$ do seu território, e apenas 2,22\% (1.240,18 $\mathrm{Km}^{2}$ ) ficam nas áreas úmidas e subúmidas.

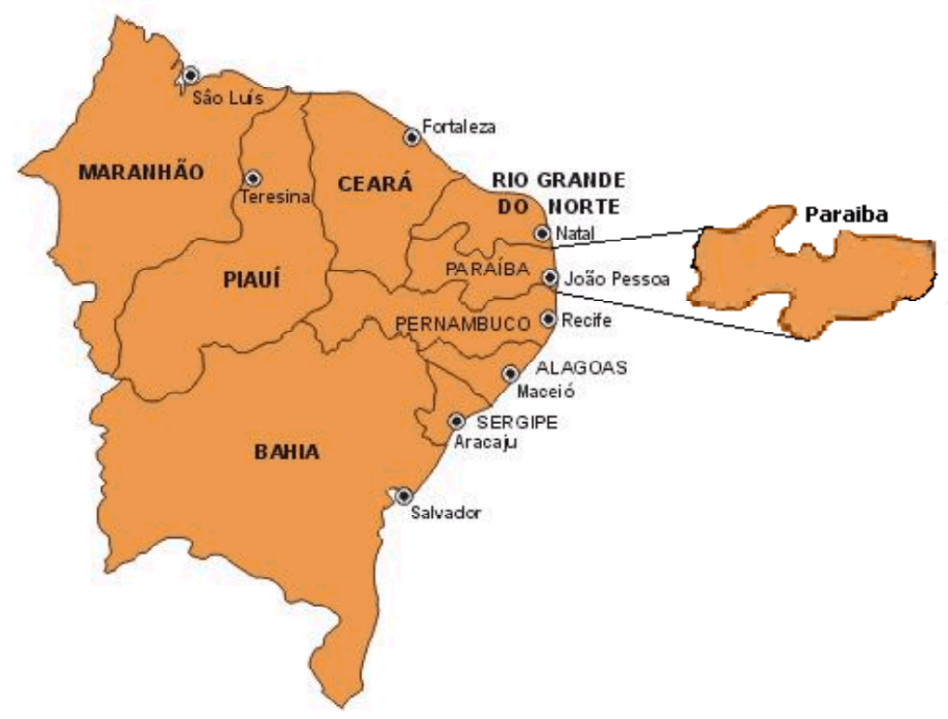

FIGURA 1 - LOCALIZAÇÃO DO ESTADO DA PARAÍBA EM RELAÇÃO AO NEB FONTE: Elaboração Própria, 2008. 
Partimos inicialmente de uma avaliação integrada através da pesquisa "in locu" e da utilização da leitura da paisagem, como também, do uso da fotointerpretação. Em face dessa etapa, consistiram num primeiro momento um bom recenseamento bibliográfico e sua interpretação, o que resultou numa série de etapas de trabalhos de campo. Por fim, espera-se contribuir, ao nível de reconhecimento, para o fornecimento de uma base concreta de informações sobre a desertificação na Paraíba, possibilitando contribuir com as atividades de planejamento ambiental e sustentabilidade do território paraibano, identificando e avaliando os impactos do homem e suas atividades nos diferentes níveis que estruturam esse meio ambiente ecológico.

As condições ambientais das Áreas Susceptíveis à Desertificação (ASD), associados à pressão exercida sobre os recursos naturais pela ação antrópica, vêm contribuindo para a deflagração de processos de desertificação em algumas das microrregiões paraibanas.

Vale salientar que os processos de exploração agrícola, em regime de agricultura irrigada ou de agricultura de sequeiro, têm contribuído para produzir impactos ambientais cada vez mais profundos capazes de potencializar os processos de desertificação. Outro aspecto, também, é o uso do solo, a pecuária extensiva e semiextensiva, a exploração mineral e dos recursos florestais das caatingas, que vêm ao longo dos anos causando profundas transformações no domínio geobotânico e morfoclimático do semiárido paraibano e acelerando processos naturais que desencadeiam a formação de núcleos de degradação ou desertificação em várias áreas, em especial na área do polígono das secas.

As causas da desertificação na Paraíba não diferem das que são encontradas em outros estados nordestinos. Elas são decorrentes do uso inadequado dos recursos naturais, de práticas agrícolas inapropriadas e, sobretudo de modelos de desenvolvimento macro e microeconômicos de curto prazo. Um outro grave aspecto a considerar são as práticas agrícolas tradicionais, geralmente associadas a um sistema concentrado de propriedade da terra e da água conduzindo a graves problemas socioeconômicos que se aprofundam quando sobrevêm as secas.

As áreas com mais evidências da Paraíba estão na microrregião dos Cariris Velhos, que abrange os seguintes municípios: Juazeirinho, São João do Cariri, Serra Branca, Cabaceiras e Camalaú; e o núcleo do Seridó (PB/RGN) mapeado desde 1977 em estudos feitos pela Sudene, com a colaboração de Vasconcelos Sobrinho. $\mathrm{Na}$ Paraíba, várias de suas microrregiões apresentam sinais, sintomas de desertificação e em algumas delas as "ulcerações do tecido ecológico", são graves. Tal é o caso das microrregiões de Monteiro, Cabaceiras, Seridó Ocidental e Oriental, Patos, entre outras. O problema já começa a se fazer notar também nas regiões subúmidas secas: Itabaiana, Salgado de São Félix, Ingá, Juarez Távora, Gurinhém, Guarabira e Tacima.

Nos estudos realizados pelo o Programa de Combate à Desertificação foram identificados 208 municípios Susceptíveis à Desertificação divididos nas seguintes áreas: nas áreas semiáridas existem 150 municípios, nas áreas subúmidas secas 47 municípios e nas áreas do entorno 11 municípios.

A Paraíba é o estado brasileiro com maior nível de desertificação, segundo dados da Organização Não Governamental Internacional Greenpeace. No relatório "Mudanças de clima, mudanças de vida" indicam o comprometimento de $29 \%$ do território paraibano, afetando indiretamente mais de 653 mil pessoas. O MMA (2008) admite que cerca de $80 \%$ dos municípios paraibanos estão numa área em que os índices pluviométricos são inferiores a $800 \mathrm{~mm}$ por ano, causando aproximadamente problemas a cerca e 1,5 milhões de pessoas.

Em diagnóstico realizado pela Superintendência do Meio Ambiente na Paraíba (SUDEMA-PB, 2008), em torno de $57,06 \%$ do território possui um grau muito alto de suscetibilidade a desertificação, que se estende do Seridó Ocidental, nos municípios de Várzea, São Mamede, até a microrregião de Sousa.

Agravando ainda muito mais ainda esses diversos relatórios, estão os números do IBAMA, colocando a Paraíba como líder do ranking dos estados que mais desmatam no Nordeste. Segundo relatório o desmatamento corresponde hoje a cerca de $70 \%$ da mata nativa, número superior ao registrado em outros estados do Nordeste, que é de $50 \%$.

O IBAMA estima que aproximadamente $17 \mathrm{mil}$ hectares de lenha sejam retirados das matas paraibanas por ano. Todos esses dados foram publicados entre os anos de 2002 e 2007, e expõem uma coisa óbvia: a expansão do semiárido paraibano, ou seja, de áreas susceptíveis a desertificação (núcleos de desertificação), onde a paisagem já evidencia a ocorrência de núcleos de desertificação, alguns deles em estado bastante avançado.

Para completar, podemos enfatizar que todos esses dados apontam para as regiões mais atingidas e marcadas periodicamente pelas secas. Estas servem de reveladoras e exarcebadoras dos processos de degradação dos recursos naturais. Três questões são comumente levantadas ao se tratar da desertificação: (i) As causas da desertificação são exclusivamente antrópicas ou elas resultam da interação entre fatores 
físicos e humanos? (ii) Não seriam elas resultantes de variações de ordem climática? (iii) Qual o papel do homem na desertificação se considerar como causa principal a interação homem-natureza?

$\mathrm{Na}$ caatinga as espécies lenhosas chamam a atenção por suas formas biológicas e pela posição dominante na estrutura da formação. Em função da magnitude dessas características, esse corresponde ao maior problema na geração dos núcleos de desertificação no estado da Paraíba. Essas espécies lenhosas de porte raquítico são as mais apreciadas para a queima em carvoarias, fornos de padarias, minério e etc. Tratamse da fácies mais seca e degradada das caatingas. Um outro aspecto a observar é que à fragilidade natural desse ecossistema traz sérias consequências para os geótopos e para as biocenoses, como também, a prática da devastação de grandes espaços pelas queimadas para as áreas de pastagem, provocando grande desequilíbrio no ecossistema e contribuindo com o processo de degradação das terras.

Candido et al (2002, p. 371-372) em estudo sobre a avaliação da degradação ambiental de parte do Seridó paraibano concluíram que:

as análises dos dados coletados em campo permitiram uma avaliação do quadro socioeconômico e ambiental, que indica alta deteriorização das condições de vida, e denuncia as dificuldades severas das famílias em que se manterem, mostrando o completo abandono do homem do campo.

E continuam: "o poder público precisa definir urgentemente políticas públicas, visando ao desenvolvimento sustentável com a diminuição dos riscos, e que venha consolidar a participação da mulher rural nas atividades socioeconômicas e familiares". Sousa et al (2007, p.100) identificaram que as causas da desertificação nos cariris paraibanos estão relacionadas às atividades humanas, tais como, "retirada da cobertura vegetal e queimadas, para implantação de agricultura de subsistência e formação de pastagens para a prática pecuarista". Todos esses fatores geram vulnerabilidades, sendo os principais impactos a perda da fertilidade dos solos por toda extensão territorial.

Para Santos e Lima (2004, p. 48):

é o desmatamento da caatinga nativa para a venda de lenha às olarias e as panificadoras locais e de outras localidades do estado, junto à fragilidade dos ecossis- temas, que tem contribuído para o aparecimento do fenômeno da desertificação, prejudicando a estrutura produtiva da região.

Segundo Neto et al (2007, p. 4407) "o que acelera o desmatamento da caatinga para a introdução consorciada das culturas de autoconsumo e pastagens, associada ä dinâmica de recomposição da vegetação nativa e suas relações com os eventos ENOS", produzindo assim, um o processo de degradação dos solos, contribuindo progressivamente para a evolução dos níveis de degradação das terras e a formação de núcleos de desertificação.

Na prática a desertificação se espalha lentamente a partir de pequenos núcleos até atingir grandes superfícies. Esses núcleos foram denominados de focos de solos desnudos ou com ulceração acentuada do tecido ecológico (llustração 1).

Ela se alimenta por si própria, criando áreas áridas que antes apresentavam certo potencial biótico. Combatê-la logo de início pode dar resultados, mas se nenhuma ação for empreendida, por falta de vontade política, parar a desertificação torna-se extremamente oneroso.

Podemos observar na llustração 1, sobre os focos e/ou núcleos uma concentração maior no Cariri e no Seridó, fato relacionado ao uso intensivo do extrativismo vegetal-mineral associado e como região fornecedora de lenha e carvão, que se estende da Mesorregião da Borborema a Zona da Mata; para o Sertão, esses focos estão mais relacionados ao modelo agropecuário, enquanto que no Agreste, está associado a pressão que a Zona da Mata exerce, tornando-a uma região de forte policultura e de grande uso das encostas úmidas do planalto da Borborema. Resumindo, suas causas e efeitos identificados na Paraíba, como um todo, são: (1) Pressão das culturas; (2) Sobrepastoreio; (3) Exploração florestal; (4) Consumo do espaço pelas culturas.

Em levantamento de campo nas cidades de Ingá, Caiçara, Cabaceiras, Santa Cecília, Patos e Catolé do Rocha verificaram-se a ocorrência de alguns núcleos de desertificação, alguns deles em estado bastante avançado. Por possuírem dinamismo próprio baseado na morfodinâmica do sistema semiárido e têm uma tendência a evoluir em detrimento das áreas vizinhas por processos regressivos de erosão, identificou-se nessas áreas elevado potencial de degradação, face as condições ecotópicas, ora localizados, ora generalizados (llustração 1). 
Observar-se também a existência de uma tendência evolutiva no tempo e no espaço, de rápida, muito rápida, lenta ou incipiente. Em alguns dos casos obser- vados a degradação já se encontra em um estágio muito avançado, podendo ser considerado irreversível.

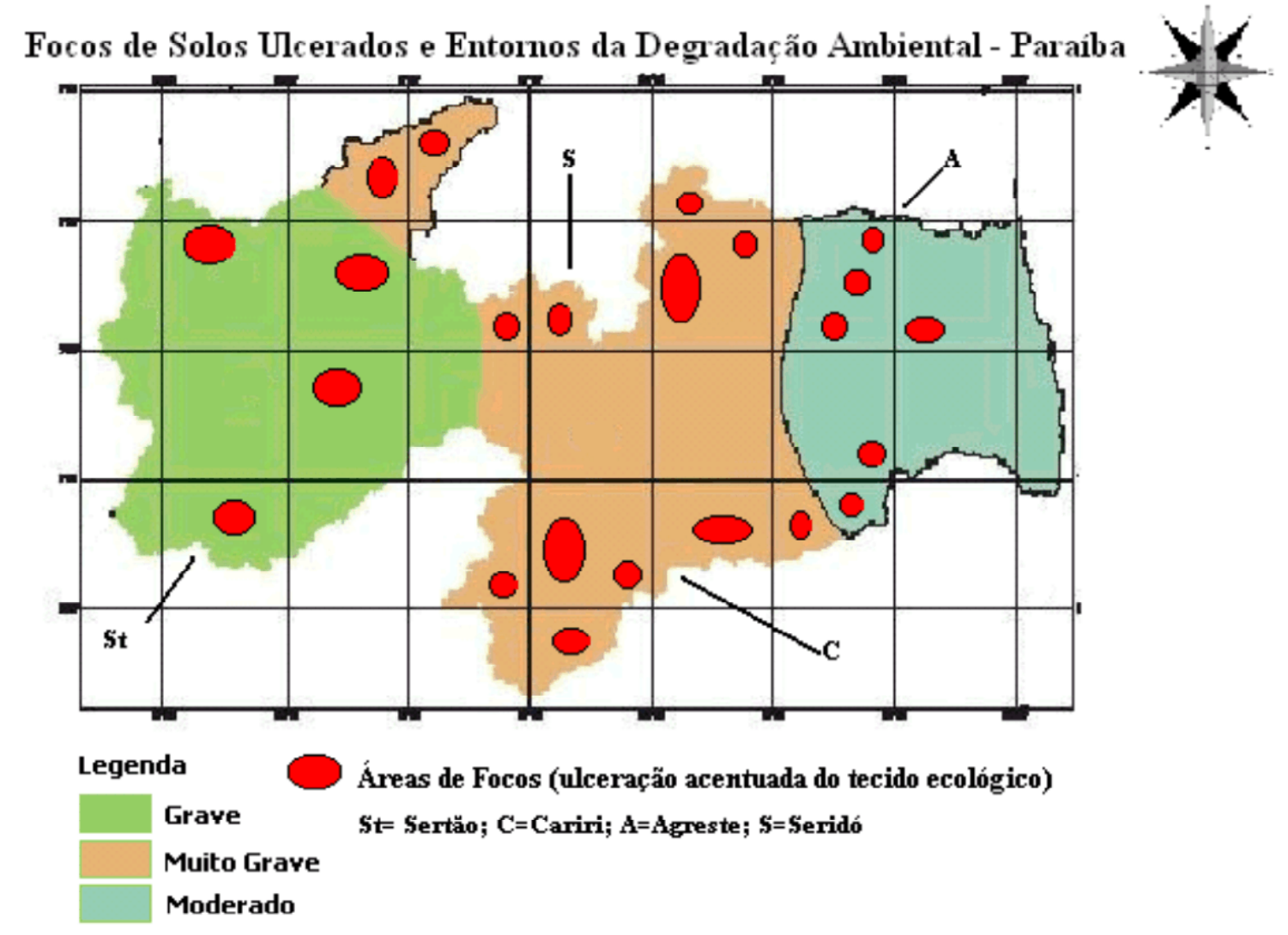

ILUSTRAÇÃO 1- NÚCLEOS DE DEGRADAÇÃO AMBIENTAL FONTE: Elaboração própria, Alves et al (2008)

Os núcleos identificados na Paraíba são:

a) áreas dedicadas ao pastoreio extensivo do gado bovino e caprino (areolares);

b) setores de tomada de empréstimo de terras marginais às estradas e açudes. Criam-se assim núcleos marginais lineares ao lado das estradas e anulares em torno dos açudes cuja recuperação é impossível ou muito difícil pois toda a massa do solo (que é muito pouco espesso) foi removida. A vegetação pioneira que consegue se instalar em alguns locais é representada por poucas espécies muito xerófilas: xique-xique, juremas (Mimosa spp.), geralmente anãs, pinhão bravo, também de pequeno porte e fumo bravo (Nicotiana glauca) indicadora de solos salinos; c) áreas lineares ao longo das instalações das linhas de transmissão de energia elétrica onde importante ravinamentos que lembram voçorocas rasas, surge e aumenta de modo irreversível. Geralmente esses sulcos e ravinas são totalmente desprovidos de vegetação;

d) áreas em torno das cidades, vilas e povoados e sedes de fazendas, em que a retirada da vegetação para lenha atinge proporções imensas com ravinamentos, solos raspados e solos decapitados (areolares circulares);

e) áreas de produção de carvão e áreas de fornos de cal e de olarias. A retirada de barro para a fabricação de telhas e tijolos vem se ampliando na medida em que se desenvolve a construção civil. Aliada a esses fatos ocorre 
a destruição da cobertura vegetal para obtenção da lenha utilizada nos fornos (pontuais e areolares);

f) áreas de passagem dos rebanhos. Formam-se caminhos em ziguezague, com solo compactado pelo excesso de pisoteio e os riscos de erosão hídrica são grandes;

g) terracetes de pisoteamento do gado nas encostas geralmente nas áreas com pastagens plantadas;

h) antigos campos cultivados- terras completamente retalhadas pela erosão hídrica;

i) construção de cercas, às vezes quilométricas, criando ao longo delas, estreitas faixas onde podem começar a ocorrer processos incipientes de degradação (erosão hídrica principalmente);

j) interflúvios pedregosos sem nenhuma vegetação que geralmente foram antes utilizados pela agricultura comercial.

Um aspecto importante nos estudos de desertificação na caatinga paraibana é que as áreas mais densamente cultivadas são os interflúvios, encostas das serras, os terraços fluviais, as abas pouco inclinadas dos vales, os pés-de-serra e as vazantes dos açudes. Nos interflúvios a vegetação é abatida e depois queimada. Efetua-se então o plantio. Após alguns anos de cultivo de milho, feijão, algodão, os campos são deixados em descanso e as capoeiras começam a ocupá-los. Estas podem ser utilizadas pelo gado após certo período de tempo e por certo prazo. Em seguida e terreno é mais uma vez desmatado e um novo ciclo de culturas se reinicia. No total são áreas consideráveis que são desmatadas e redesmatadas a cada ano.

Após identificar as causas e efeitos da degradação ambiental, oriundas das condições edafoclimáticas e das transformações econômicas e sociais ocorridas ao longo do seu processo de ocupação, consideramos que esta situação da Paraíba também é encontrada nos estados vizinhos, ou seja, nas regiões semiáridas, e se constitui numa verdadeira "ameaça" ao desenvolvimento sustentável da economia nordestina. Podemos agrupar esses núcleos em vulnerabilidades, como marcos centrais para uma política de desenvolvimento sustentável: a ambiental, a econômico-social, a científico-tecnológica e do estado.

A vulnerabilidade geoambiental mais destacada, naturalmente, é a desertificação, tanto no aspecto edafoclimatológico como socioeconômico, sendo um problema que continua fornecendo adubo às ideias regionalistas e se constitui parte essencial da identidade nordestina.

No entanto, os efeitos da desertificação serão tão reais quanto os efeitos da seca que são devastadores sentidos pela população mais pobre e sobre a economia rural da região. Por outro lado, a preocupação com a seca por parte do estado é tão secular quanto à inutilidade de suas ações para o seu combate, consumiram-se tantos recursos públicos quanto foram apropriados pelas oligarquias rurais que os administrava.

Nesse aspecto, a sustentabilidade nas regiões semiáridas tem de estar acompanhada de uma política de combate à desertificação considerando todos os itens analisados. Essa luta contra a desertificação deve ser baseada em três esferas: (I) Uma aceitação realista dos fatos geoecológicos, isto é: precipitações fracas e irregulares; recorrência imprevisível de longos períodos secos; um potencial fraco por unidade de superfície, donde decorre a necessidade de unidades de manejo bastante grandes para compensar a variabilidade das precipitações no espaço no decorrer de qualquer ano; ecossistemas frágeis e instáveis naturalmente; e graves riscos de erosão, de acumulação e de salinização dos solos. (II) Uma percepção adequada dos critérios econômicos e das atitudes sociais, através de um amplo programa de educação ambiental; e (III) A disposição de bons estudos capazes de fornecer uma sólida avaliação de cada unidade ecológica em função das estratégias de desenvolvimento e dos investimentos possíveis.

Mas, as soluções técnicas para se combater a desertificação só poderão ser aplicadas se houver uma forte vontade política para aplicá-las. No semiárido nordestino estas soluções necessitam de uma verdadeira revolução sociocultural e política o que implica numa profunda interferência no sistema de propriedade de terra e na vida das populações envolvidas.

Além do mais cabe lembrar uma consideração tão importante quanto essas práticas para estabilização e combate da desertificação na Paraíba e no Nordeste do Brasil, pois:

o grande problema do Nordeste semiárido não é de ordem física. Ela é social. No dia em que for adotada uma política que beneficie toda a população e não apenas os grupos econômicos externos à região e à oligarquia local, o problema será solucionado. (ANDRADE, 1989, p. 397). 
ALVES, J. J. A.; SOUZA, E. N.; NASCIMENTO, S. S. Núcleos de desertificação...

\section{CONSIDERAÇÕES FINAIS}

O Processo de desertificação tem aumentado no mundo inteiro, mas poderia ser amenizado com a participação de todos, dos governos com investimentos para orientar a população a utilizar de forma adequada os recursos naturais, elaborando projetos de acordo com a necessidade de cada região, incentivar o cultivo de culturas que sejam apropriados ao tipo de clima e solo.

Pois se todos tiverem consciência no sentido de cuidar e utilizar de forma de maneira adequada os elementos da natureza, para que no futuro tenhamos uma qualidade de vida, caso contrário à tendência é piorar o nosso bem estar e o nosso meio ambiente.

Por fim, convém lembrar que de acordo com dados citados por Santana (2007, p.27), as áreas suscetíveis à desertificação no Nordeste brasileiro correspondem em média de $57 \%$ do território da região, cerca de 89 milhões de hectares. Isso representa um perigo para $10,5 \%$ da área total do país e abrange 1.031 municípios.

As razões apresentadas neste artigo sobre a desertificação consideram que qualquer programa de combate à desertificação passa pela luta contra a deteriorização dos recursos naturais e de práticas socioeconômicas sustentáveis. De conformidade com Alves (2007b, p.105) "a insustentabilidade, sendo de dimensões desproporcionais, depara-se com perspectivas catastróficas pela rápida debilitação das condições de vida na biosfera". Nessa ótica conclui-se que, somente através da prática da sustentabilidade é capaz de evitar o colapso das sociedades futuras.

Concluindo, parafraseamos o geógrafo e Prof. Manoel Correia de Andrade, em seu último artigo, escrito ao Jornal do Comércio - PE, em 01 de julho de 2007:

Não se pode admitir uniformidade para o semi-árido nordestino, uma vez que condições meteorológicas, geológicas e morfológicas provocam modificações nas suas diversas áreas, havendo trechos em que o clima pode ser considerado como semi-úmido e trechos onde pode ser considerado como semi-árido.

Por fim, a luta contra a desertificação tanto na Paraíba, como nas demais regiões do semiárido brasileiro, como sugestão, deve ser baseada em:

1. Uma aceitação realista dos fatos geoecológicos, isto é: (i) precipitações fracas e irregulares; (ii) recorrência imprevisível de longos períodos secos; (iii) um potencial fraco por unidade de superfície, donde decorre a necessidade de unidades de manejo bastante grandes para compensar a variabilidade das precipitações no espaço no decorrer de qualquer ano; (iv) ecossistemas frágeis e instáveis naturalmente; (v) graves riscos de erosão, de acumulação e de salinização dos solos.

2. Uma percepção adequada dos critérios econômicos e das atitudes sociais;

3. A disposição de bons estudos capazes de fornecer uma sólida avaliação de cada unidade ecológica em função das estratégias de desenvolvimento e dos investimentos possíveis.

Assim, como na Paraíba, o tratamento aos demais estados nordestinos no combate à desertificação só produzirá grandes efeitos se for considerado que nessas regiões não é uniforme, e cada caso é em particular um estudo de caso, ou seja, cada foco contém uma interação específica com o meio e o homem. Isso significa medidas específicas para o Cariri, Sertão, Seridó e Agreste, como também, uma aceitação realística de que existem fatores geoecológicos sendo intensificados pelo antropismo.

\section{REFERÊNCIAS}

ALVES, J. J. A. Geoecologia da Caatinga no Semi-Árido do Nordeste brasileiro. Revista Climatologia e Estudos da Paisagem. Rio Claro, UNESP, v. 2, n. 1, janeiro/junho 2007a.

ALVES, J. J. A. Bio-Geografia. João Pessoa: Fotograf, 2007b. p.108.

ANDRADE, M. C. de. L'intervention de l'Etat et la sécheresse dans le Nordeste du Brésil. In: BRET, Bernard (coord.)Les hommes face aux Sécheresses. p. 391-398. Coll. Travaux et Mémoires de L'IHEAL, $n^{\circ} 42$ - Série Thèses et Colloques, n.1. Ed. EST/ IHEAL, Paris, 1989.

BERTONI, J.; NETO, F. L. Conservação do solo. 4 ed. São Paulo: Ícone, 1999.

CANDIDO, H. G.; BARBOSA, M. P.; SILVA, M. J. da. Avaliação da degradação ambiental de parte do Seridó Paraibano. Revista Brasileira de Engenharia Agrícola e Ambiental, 
ALVES, J. J. A.; SOUZA, E. N.; NASCIMENTO, S. S. Núcleos de desertificação...

Campina Grande, v. 6, n. 2. 2002.

DREW, D. Processos interativos homem-meio ambiente. 4 ed. Rio de Janeiro: Bertrand Brasil, 1998. p. 224.

MAINGUET, M. Stratégies de combat contre la degradation de l'environnement dans les ecosystèmes secs: les responses des Nations Unies, de la C.E.I., de la Chine et du Sahel. Bull. Assoc. Géograph. França, Paris, n.5 p. 422-433. 1992.

MATALLO JÚNIOR, H. Indicadores de Desertificação: Histórico e Perspectivas. Brasília: UNESCO, 2001. p. 126.

MMA. Ministério do Meio Ambiente. Disponível em: <http:// www.mma.gov.br> Acesso em: 21/6/2008.

NETO, A. F. da S.; BARBOSA, M. P.; NETO, J. M. de M. A dinâmica da desertificação e a influência dos eventos ENOS na degradação das terras em municípios o Cariri Ocidental (Paraíba - Brasil). In: SIMPÓSIO BRASILEIRO DE SENSORIAMENTO REMOTO, 13., 2007, Florianópolis. Anais... Florianópolis, 2007. p. 4405-4412.

PAN BRASIL. Programa de Ação Nacional de Combate à Desertificação e Mitigação dos Efeitos da Seca. Ministério do Meio Ambiente. Brasília - DF. p. 213. 2005.

SANTANA, M. O. (Org). Atlas das áreas susceptíveis a desertificação do Brasil /MMA. Secretaria de Recursos Hídricos, Brasília, MMA, 2007.
SANTOS, J. S. dos; LIMA, E. R. V. de L. Análise do processo de desertificação no município de Picuí - PB através de indicadores sócio-ambientais. In: SIMPÓSIO BRASILEIRO DE GEOGRAFIA FÍSICAAPLICADA, 10, 2004.

SOUSA, R. F. de; BARBOSA, M. P.; NETO, J. M. de M.; FERNANDES, M. de F. Estudo do Processo da Desertificação e das Vulnerabilidades do Município de Cabaceiras - Paraíba. Rev. Engenharia Ambiental - Espírito Santo do Pinhal, v. 4, n. 1, p. 89-102, jan/jun 2007.

SUDEMA. Superintendência de Administração do Meio Ambiente. Atualização do Diagnóstico Florestal do Estado da Paraíba - João Pessoa; SUDEMA, p. 268. 2004.

SUDEMA. Superintendência de Desenvolvimento e Meio Ambiente da Paraíba. Disponível em: <http://www.sudema. pb.gov.br> Acesso em: 29/5/2008.

SUERTEGARY, D. M. A. Desertificação: Recuperação e Desenvolvimento Sustentável. In: GUERRA, A. J. T.; CUNHA, S. B. da, (Org.). Geomorfologia e Meio Ambiente. Bertrand Brasil, 1996. p. 372.

UNCOD. Desertification: its causes and consequences. Secretaria das Nações Unidas. Conference on Desertification, Pergamon, Press, Nairobi, Kenya, 1977.

VASCONCELOS SOBRINHO, J. Processos de desertificação no Nordeste do Brasil: sua gênese e sua contenção. Recife: Sudene, 1983. 


\section{RA’E GA: O ESPAÇO GEOGRÁFICO EM ANÁLISE}

ISSN $2177-2738$

\section{DIRETRIZES PARA O AUTOR}

A revista $R A^{\prime} E$ GA - O Espaço Geográfico em Análise é um veículo de publicação do Departamento de Geografia e Programa de Pós-graduação em Geografia da Universidade Federal do Paraná, sendo que ela recebe contribuições científicas na forma de texto relacionadas à ciência geográfica e áreas afins. Os artigos são submetidos à apreciação do Conselho Editorial da Revista, que acata ou não a publicação. Essa decisão será comunicada aos autores via e-mail, sem compromisso de devolução dos originais.

\section{I - Orientação geral}

1. O original deverá ser submetido ao sistema eletrônico de revistas: SER (www.ser.ufpr.br/raega), além de uma cópia em CD-R a ser enviada para o Editor Científico para fins de arquivo (depois de submetida ao sistema SER).

2. Os artigos devem ter de 10 a 30 páginas digitadas, incluindo figuras, tabelas e referências. Em casos especiais, a serem avaliados pelos editores, serão aceitos originais com número superior de páginas.

3. Os artigos serão preferencialmente escritos em português ou espanhol.

\section{II - Formato do texto}

1. Os textos dos trabalhos devem ser digitados em computadores tipo IBM-PC utilizando-se o programa MICROSOFT WORD FOR WINDOWS. Os textos devem ser digitados em letra Arial, corpo 12, com indicação de parágrafo, espaçamento 1,5, respeitando as normas da ABNT .

2. As figuras devem ser enviadas em formato digital BMP,.TIFF (não comprimido) ou .JPG e, no caso de tabelas e gráficos, devem ser feitos com o MICROSOFT WORD FOR WINDOWS ou MICROSOFT EXCEL, devidamente acompanhados de cópia em papel, e respeitando as medidas máximas de $21 \mathrm{x}$ $27,5 \mathrm{~cm}$. O texto deve indicar o local das figuras e tabelas.

3. As figuras serão publicadas preferencialmente em preto e branco. Se houver necessidade das figuras serem publicadas coloridas, o custo ficará a cargo do autor. Nesse caso deve ser consultado o editor.

4. Figuras e tabelas devem apresentar título e legendas em português ou espanhol.

\section{III - Organização dos textos}

Na primeira folha deverá constar o título (português e inglês), nome(s) do(s) autor(es), vínculo institucional e titulação. Na segunda página deverá constar o resumo (inglês e português) em um único parágrafo que contenha entre 5 e 10 linhas e palavras-chave (no máximo cinco palavras).

\section{IV - Referências e citações}

De acordo com a NBR-10520:2001 da ABNT, as referências deverão ter chamadas no texto pelo(s) sobrenome(s) do(s) autor(es), em maiúsculas, com data e paginação, quando dentro de parêntesis: (SANTOS, 1995, p.90) e apenas com a primeira letra em caixa alta, com as outras em caixa baixa, quando inseridas na frase: Segundo Santos (1995, p.8). Caso um mesmo autor citado tiver mais de uma publicação no mesmo ano, identificar cada uma delas por letras, (SANTOS, 1995a, p.6). Somente as referências citadas no texto deverão constar ao final do texto, em ordem alfabética, e elaborada de acordo com a NBR-6023:2000 da ABNT. 


\section{Livros}

SOBRENOME, Nomes. Título do livro. Local de Edição: Editora, data.

\section{Partes de livros}

SOBRENOME, Nomes (do autor do capítulo). Título do capítulo. In: SOBRENOME, Nomes (Ed., Org., Comp.) Título do livro. Local de Edição: Editora, ano. Número do Capítulo, p. página inicial - página final do capítulo.

\section{Artigos de periódicos}

SOBRENOME, Nomes. Título do artigo. Título do Periódico, Local de publicação, número do volume, número do fascículo, p. página inicial - página final, ano.

\section{Trabalhos acadêmicos}

SOBRENOME, Nomes. Título do trabalho acadêmico. f. Tese/Dissertação/Monografia (Doutorado/Mestrado/ em ...) - Setor, Universidade, local da defesa, data de defesa.

\section{Trabalhos em eventos}

SOBRENOME, Nomes. Título do trabalho. In: NOME DO EVENTO EM CAIXA ALTA, número do evento, ano de realização, local. Título...(Anais, Atas, Proceedings e etc.). Local de publicação: Editora, data, página inicial-final.

\section{Artigos de periódicos online}

SOBRENOME, Nomes. Título do trabalho. Fonte. Disponível em: <endereço eletrônico>. Acesso em: data (dia/mês/ano).

As citações textuais de até três linhas deverão aparecer no decorrer do texto, na mesma letra e entre aspas. As citações de mais de três linhas deverão ser digitadas com recuo, sem aspas nem itálicos e em letra de tamanho menor do que aquela do texto principal. Em ambas as citações deve ser referido o SOBRENOME do autor, ano, página.

RA'E GA: O Espaço Geográfico em Análise

Av. Cel. Francisco H. dos Santos, 100 - Jardim das Américas - Centro Politécnico

CEP 81532980 - Caixa Postal 19001 - Curitiba - PR

Fone: (41) 3361-3454 - Fax (41) 3361-3244

e-mail: raega@ufpr.br - web site: www.geografia.ufpr.br/raega 


\section{RA’E GA: O ESPAÇO GEOGRÁFICO EM ANÁLISE}

ISSN $2177-2738$

\section{INSTRUCTIONS TO AUTHORS}

The RA'E GA - O Espaço Geográfico em Análise journal, published by the Department of Geography and the Post-Graduate Studies Program in Geography - Master's and Doctorate's Level of the Federal University of Paraná, receives scientific contributions related to the geographic science and related areas. Articles may be published once approved by the Editorial board. Authors who submitted papers will receive the Editorial board's decisions by e-mail. Originals of submitted papers may not be returned to authors.

\section{I - General rules}

1. Originals should be sent to SER (Electronic Journal System) at the following address: <www.ser.ufpr.br/ raega>. After that, a CD-R copy must be sent to the Editor to be part of our filing system.

2. Papers should not be longer than 30 pages and not shorter than 10 pages, including fi gures, tables and references. In some special cases, which will be analyzed by the Editor, longer originals may be submitted.

3. Papers should be written either in Portuguese or in Spanish.

\section{II - Text format}

1. Papers should be typed in IBM-PC computers; MICROSOFT WORD FOR WINDOWS program should be used. They also should be typed in Arial letters, size 12, 1.5 spaced lines indenting first lines of paragraphs; ABNT rules should be followed.

2. Figures should be sent in BMP, .TIFF (not compressed) or .JPG digital format. Tables and graphics should be done by means of MICROSOFT WORD FOR WINDOWS or MICROSOFT EXCEL. Figures, tables and graphics should be sent printed, and they should not exceed $21 \times 27,5 \mathrm{~cm}$. Texts should indicate the appropriate place for figures and tables.

3. Figures should be published in black and white. Authors should agree to pay for additional costs in case of colored figures; these cases will be analyzed by the Editor.

4. Figures and tables should have titles and subtitles either in Portuguese or Spanish.

\section{III- Text organization}

The first page should contain: the title (both in Portuguese and in English), the author's names, Institution and titles. The second page should include an abstract (both in Portuguese and in English), in an only paragraph with 5 to 10 lines, and at most 5 (fi ve) key words.

\section{IV - References and citations}

According to NBR-10520:2001 from ABNT, the references should be called in the text by the author's surname in capital letters, date and page when in parenthesis (SANTOS, 1995, P. 90) and in small letters when within a sentence: According to Santos $(1995$, p. 8). If the same cited author has more than one publication in the same year, each one should be identified with letters, (SANTOS, 1995a, p. 6). Only the references that have been cited in the text should be mentioned in the reference list, in alphabetical order and created according to the NBR-6023:2000 from ABNT. 


\section{Books}

SURNAME, Names. Title. Place: Publisher name, date.

\section{Parts of books}

SURNAME, Names (chapter author). Chapter title. In: SURNAME, Names (Eds.; Org.). Book title. Place: Publisher name, year. Chapter number, chapter page number range (p. 10-18).

\section{Periodical articles}

SURNAME, Names. Article title. Journal Title. Place, volume number, issue number, p. page number range, year.

\section{Academic reports}

SURNAME, Names. Report title. Total page number. Thesis/Dissertation/Monograph (Doctory/ Mastery in ...) - School of ..., University, Place, date.

\section{Papers presented at meetings}

SURNAME, Names. Paper title. In: CONFERENCE NAME IN CAPITAL LETTERS, conference number, year, Place. Title... (Annals, Acts, Proceedings). Place: Publisher name, date, page number range.

\section{Online journal articles}

SURNAME, Names. Article title. Publisher. Journal Title. Place, volume number, issue number, p. page number range, year/date. Available at: <http://address>. Captured in: day/month/year.

Quotations of three lines or shorter should be showed in "quotation marks" and in the same font-size in the running text. Quotations of more than three lines should be indented at the left margin throughout, without any quotation marks or italics and in a smaller font than the main text. Both must be referred to as AUTHOR'S SURNAME, year, pages.

RA'E GA: O Espaço Geográfico em Análise

Av. Cel. Francisco H. dos Santos, 100 - Jardim das Américas - Centro Politécnico

Zip Code: 81532980 - P.O. Box: 19001 - Curitiba - PR

Phone number: (41) 3361-3454 - Fax number: (41) 3361-3244

e-mail: raega@ufpr.br - web site: www.geografia.ufpr.br/raega 


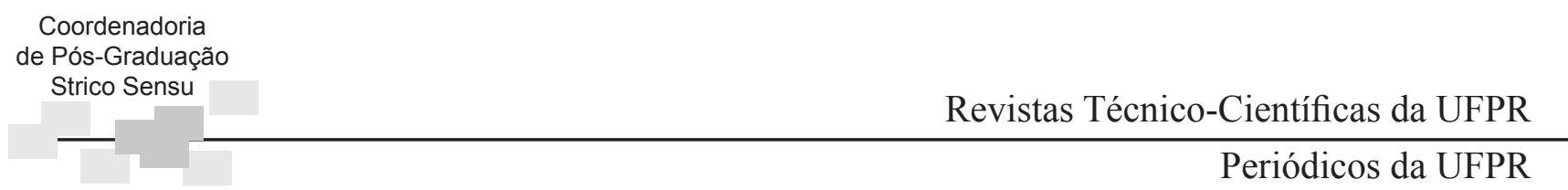

A Universidade Federal do Paraná instituiu o Sistema Eletrônico de Revistas (SER), abrindo um importante canal de interação entre usuários e a comunidade científica. Neste espaço estão listadas as Revistas Técnico-Científicas publicadas com recursos próprios ou com recursos do programa de apoio à publicação instituído pela UFPR.

O SER utiliza-se do Open Journal System, software livre e com protocolo internacional que permite a submissão de artigos e o acesso às revistas de qualquer parte do mundo. Nesse sistema já estão cadastradas 42 revistas da UFPR, abrangendo diversas áreas de conhecimento.

O sistema pode ser acessado por AUTORES, para a submissão de trabalhos, CONSULTORES, para a avaliação dos trabalhos, EDITORES, para o gerenciamento do processo editorial e USUÁRIOS, interessados em acessar e obter CÓPIAS de artigos já publicados nas revistas.

A SUBMISSÃO de artigos é feita por meio eletrônico e o autor poderá fazer o ACOMPANHAMENTO do processo de AVALIAÇÃO por parte dos consultores até a editoração final do artigo. As NORMAS de publicação e demais instruções, bem como os endereços dos editores são encontrados nas páginas de cada revista.

O trabalho de editoração de algumas revistas (Boletim Paranaense de Geociências, Desenvolvimento e Meio Ambiente, Educar em Revista, Extensão em Foco, História: Questões \& Debates, RA’E GA: O Espaço Geográfico em Análise, Revista de Economia e Revista Letras ) é supervisionado pela EDITORA UFPR, que conta com corpo editorial especializado que se ocupa da revisão final dos volumes de seus respectivos periódicos, dentro dos padrões estabelecidos pela Editora. Findo o processo de editoração, uma cópia (pdf) dos artigos é disponibilizada em meio digital, dentro do Sistema SER, enquanto outra segue para impressão nas gráficas determinadas para cada publicação.

Para submeter um trabalho pela primeira vez será, antes, necessário entrar em CADASTRO. Uma vez cadastrado, abre-se uma caixa de diálogo indicando os passos a serem seguidos para o processo de submissão do artigo. Desejando apenas consultar trabalhos já publicados, basta acessar ARQUIVOS e obter o artigo desejado.

O SER oferece ainda o Public Knowledge Project, poderosa ferramenta de pesquisa, com acessibilidade global. Para fazer a busca por um tema de seu interesse utilizando essa ferramenta basta clicar em PKP e, em seguida, digitar uma palavra-chave na caixa de diálogo. Com isso você acessará artigos sobre o tema de seu interesse publicados em diversas partes do mundo.

Universidade Federal do Paraná

Pró-Reitoria de Pesquisa e Pós-Graduação (PRPPG)

R. Dr. Faivre, 405 - Ed. D. Pedro II, $1^{\circ}$ andar, Curitiba, Paraná, Brasil

CEP: 80060-140 - Telefone: (41) 3360-5227/ 3360-5335 - FAX: (41) 3360-5113

ser@ufpr.br

prppg@ufpr.br 